DOI: https://doi.org/10.24127/ajpm.v10i4.4180

\title{
PROSES BERPIKIR SISWA TUNAGRAHITA RINGAN DALAM MEMAHAMI KONSEP GEOMETRI BERDASARKAN TEORI JEAN PIAGET
}

\author{
Yosepha Patricia Wua Laja ${ }^{1 *}$,Justin Eduardo Simamarta ${ }^{2}$, Ferdinandus Mone $^{3}$ \\ ${ }^{1,2,3}$ Pendidikan Matematika Universitas Timor, Kota Kefamenanu, Indonesia \\ *Corresponding author. Jalan Eltari Km.9 Kefamenanu ,85613, Kefamenanu, Indonesia \\ E-mail: $\quad y$ osephalaja@unimor.ac.id ${ }^{*}$ \\ justinesimarmata@unimor.ac.id ${ }^{2)}$ \\ ferdimone@gmail.com ${ }^{3)}$
}

Received 30 August 2021; Received in revised form 04 December 2021; Accepted 21 December 2021

\begin{abstract}
Abstrak
Anak berkebutuhan khusus $(\mathrm{ABK})$ dalam hal ini tunagrahita tentunya memiliki proses berpikir yang berbeda dengan anak normal lainnya. Oleh karena berbeda maka perlu ada kajian tentang proses berpikirnya dengan tujuan menemukan suatu solusi untuk mengatasi masalah-masalah yang sering dihadapi siswa tunagrahita dalam pembelajaran matematika. Tujuan penelitian ini adalah untuk mendeskripsikan proses berpikir siswa tunagrahita dalam memahami konsep geometri berdasarkan teori Jean Piaget. Subjek penelitian ini adalah dua siswa tunagrahita yang berada di kelas VI. Tahapan penelitian yang dilakukan adalah melakukan proses pembelajaran selama tiga hari berturut-turut untuk mengenali geometri menggunakan alat peraga kemudian di akhir kegiatan, siswa tunagrahita diberikan soal evaluasi berbentuk make a match. Hasil penelitian menunjukkan bahwa kedua siswa tunagrahita mengalami beberapa kali disequilibrium hingga akhirnya mengalami proses asimilasi dan akomodasi. Namun hanya satu siswa saja yang mengalami equilibrium yang dapat menghubungkan bangun datar dan bangun ruang berdasarkan hasil kegiatan pengamatannya. Proses pembelajaran bagi siswa tunagrahita haruslah dilakukan berulang-ulang hingga mereka sampai pada pemahaman akan matematika.
\end{abstract}

Kata kunci: Geometri; Jean Piaget; Proses Berpikir; Tunagrahita

\begin{abstract}
Mental retardation certainly has a different thought process from other normal children. Because it is different, there needs to be a study of the thought process with the aim of finding a solution to overcome the problems that are often faced by mentally retarded students in learning mathematics. The purpose of this study was to describe the thought process of mentally retarded students in understanding geometric concepts based on Jean Piaget's theory. The subjects of this study were two mentally retarded students who were in class VI. The stages of the research carried out were carrying out a learning process for three consecutive days to recognize geometry using visual aids then at the end of the activity, mentally retarded students were given evaluation questions in the form of make a match. The results showed that the two mentally retarded students experienced disequilibrium several times until they finally experienced the process of assimilation and accommodation. However, only one student experienced equilibrium who was able to connect flat figures and spatial figures based on the results of their observations. The learning process for mentally retarded students must be repeated until they arrive at an understanding of mathematics.
\end{abstract}

Keywords: Geometry; Jean Piaget ; Thinking Process; Mental Retardation

Thisis an open access article under the Creative Commons Attribution 4.0 International License

\section{PENDAHULUAN}

Undang-Undang RI Pasal 5

Nomor 20 Tahun 2003 tentang Sistem
Pendidikan Indonesia menekankan bawa pendidikan diberikan bagi setiap Warga Negara Indonesia tidak 
terkecuali bagi warga negara yang memiliki kelainan fisik, emosional, mental, intelektual, dan/atau sosial, serta yang memiliki potensi kecerdasan dan bakat khusus. Salah satu anak berkebutuhan khusus adalah Tunagrahita. Siswa tunagrahita cenderung memiliki daya intelektual yang rendah jika dibandingkan dengan siswa yang bukan tunagrahita (Nurfaidah, 2020).

Sekalipun siswa tunagrahita ringan memiliki daya intelektual yang rendah, mereka pun mengalami proses berpikir (Agustina, 2021; Usodo, Sandie, \& Riyadi, 2013; Widyastuti, 2015). Proses berpikir merupakan kegiatan mental yang melibatkan kognitif untuk menyelesaikan suatu masalah atau mengembangkan suatu gagasan tertentu (Alifah \& Aripin, 2018; Rahman, 2010; Widyastuti, 2015). Selain itu dalam proses berpikir terdapat beberapa proses yang terjadi yaitu equilibrium, asimilasi, akomodasi, disequilibrium (Piaget, 1969; Subanji \& Supratman, 2015; Usodo et al., 2013).

Namun dari beberapa penelitianpenelitian sebelumnya, belum banyak yang meneliti tentang proses berpikir Piaget siswa tunagrahita pada materi Geometri. Selain itu juga, tidak adanya penelitian yang meneliti di SDLB Benpasi Kefamenanu. Padahal banyak permasalahan yang dialami para siswa di sekolah ini dalam belajar matematika. Salah satunya adalah dalam memahami materi matematika yang abstrak khususnya geometri. Hal ini dibuktikan berdasarkan hasil wawancara langsung bersama dua siswa yang bersangkutan dan bukti bahwa nilai matematika yang mereka peroleh pada materi ini berada di bawah rata-rata. Idealnya, materi ini penting untuk dipelajari karena melalui geometri siswa dapat menghubungkan antara konsep matematika yang bersifat abstrak dengan konsep matematika yang bersifat konkret sehingga mudah mengaitkan antara keduanya dan dapat menjadi stimulus terhadap pemahaman yang mendalam (Maulani \& Zanthy, 2020; Pratama, Irdamurni, \& Zulmiyetri, 2013).

Salah satu alasan kesulitan yang dialami oleh kedua siswa tunagrahita ringan ini adalah karena keterbatasan proses berpikir yang memberikan konsekuensi pada kesulitan mereka dalam mengikuti pelajaran akademik matematika pada materi geometri (Basori \& Gunawan, 2018). Oleh karena itu, penelitian ini hadir untuk mendeskripsikan proses berpikir siswa tunagrahita ringan SLB Benpasi Kefamenanu dalam memahami konsep geometri berdasarkan teori belajar Jean Piaget.

Proses berpikir siswa tunagrahita ini perlu diketahui agar guru dapat memiliki gambaran tentang proses berpikir mereka dan menentukan metode pembelajaran yang tepat untuk diterapkan (Fadillatul \& Sopandi, 2020; Suryadinata \& Farida, 2016; Utami, Sujadi, \& Riyadi, 2014) demi meningkatkan dan menjaga kualitas pembelajaran matematika bagi siswa tunagrahita ringan di SDLB Benpasi Kefamenanu.

\section{METODE PENELITIAN}

Tahapan penelitian ini diawali dengan memberikan penyajian materi geometri dalam hal ini bangun ruang dan bangun datar menggunakan bantuan alat peraga selama tiga hari berturutturut. Kemudian siswa diberi soal untuk mencocokan suatu gambar ke dalam konsep bangun datar ataukah bangun ruang.

Subjek penelitian ini adalah siswa SDLB Benpasi Kefamenanu kelas VI sebanyak 2 siswa tunagrahita ringan. 
Teknik pemilihan subjek menggunakan teknik purposive sampling. Instrumen yang digunakan dalam penelitian ini adalah soal tes dan pedoman wawancara.

Teknik pengumpulan data adalah tes dan wawancara. Pada penelitian ini digunakan triangulasi waktu dimana pengumpulan data dilakukan sebanyak dua kali dalam waktu yang berbeda. Teknik analisis data yang digunakan mengikuti prosedur Miles dan Huberman yang terdiri dari reduksi data, penyajian data dan penarikan kesimpulan. Data yang dianalisis adalah hasil jawaban soal tes dan hasil wawancara. Analisis data dilakukan berdasarkan indikator proses berpikir berdasarkan tahapan Jean Piaget (Aini, Susanto, \& Trapsilasiwi, 2018; Rahman, 2010).

\section{HASIL DAN PEMBAHASAN}

Dua siswa tunagrahita ringan yang ada di SLB Benpasi Kefamenanu berada di kelas VI SD akan dilabeli siswa T1 dan T2. Pada awalnya siswasiswa diberi materi mengenai bangun ruang maupun bangun datar dalam 3 hari berturut-turut menggunakan alat peraga bangun datar dan bangun ruang. Kemudian hari terakhir, mereka diberi latihan soal mencocokan bangunbangun mana saja yang tergolong dalam bangun ruang maupun bangun datar.

T1 sedikit mengalami gangguan pendengaran, sehingga dalam pembelajaran matematika menggunakan bahasa isyarat yang dibantu oleh kawannya. Sejak pertama menerima bentuk latihan soal, T1 diberi penjelasan mengenai langkah-langkah yang ia perlu lakukan,dan T1 memahami langkah-langkah yang dijelaskan. Pertama T1 terlihat bingung dalam menentukan gambar mana yang merupakan bangun ruang (balok dan
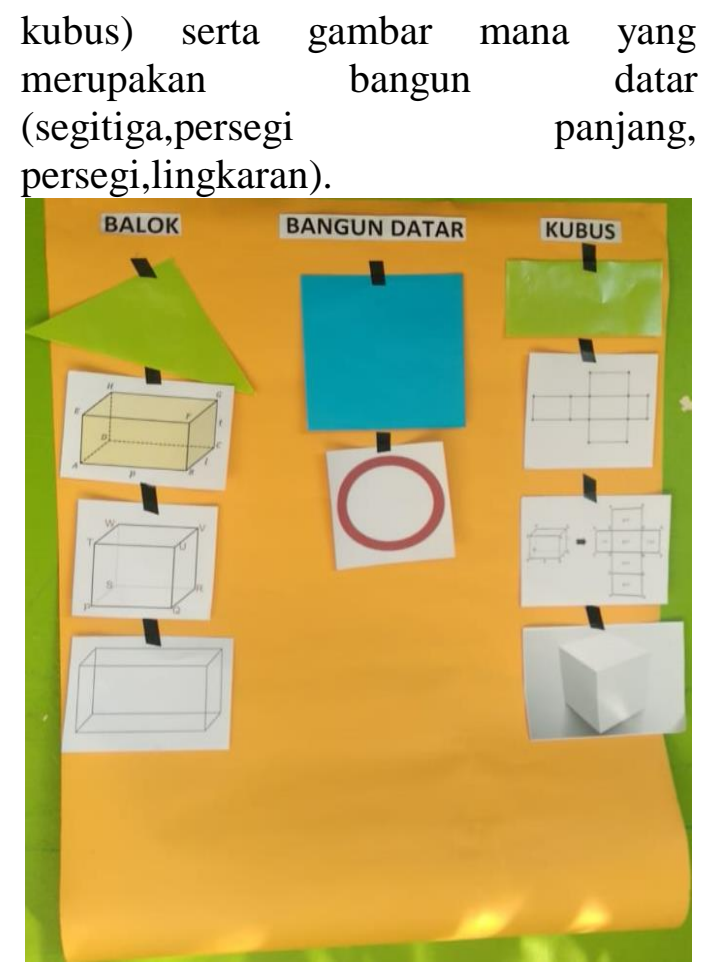

Gambar 1. Hasil Pekerjaan T1

Sejak awal, T1 mengalami disequilibrium karena ia tidak dapat menentukan bangun mana yang merupakan bangun ruang (balok dan kubus). Terlihat pada gambar 1, T1 keliru memilih gambar segitiga dan persegi panjang merupakan bangun ruang (balok dan kubus). Tetapi T1 mengalami proses asimilasi saat ia dapat memilih gambar persegi merupakan bangun datar. Saat inilah T1 diminta untuk memberikan alasan mengapa persegi merupakan bangun datar sementara segitiga dan persegi panjang merupakan bangun ruang.

T1 kembali mengalami disequilibrium karena tidak dapat memberikan alasan dengan tepat. Oleh karena itu, T1 diberi penjelasan tambahan bahwa bangun datar hanya memiliki dua dimensi yaitu panjang dan lebar sehingga T1 meyadari bahwa ia telah salah menentukan gambar mana yang termasuk bangun ruang (balok dan kubus). Pada saat ini T1 kembali mengalami proses asimilasi diikuti 
dengan T1 dapat menyebutkan contoh bangun datar yang ada di sekitarnya seperti meja, spanduk, keset, buku tulis, mistar. Selain itu, T1 mengalami proses akomodasi ketika T1 dapat menentukan dan menunjukkan unsur-unsur bangun datar sambil T1 menunjukkan yang mana panjang dan yang mana lebar.

Kegiatan pun lanjut ketika T1 diminta untuk menunjukkan gambargambar mana yang termasuk bangun ruang (balok dan kubus). Dari enam gambar yang dicocokan,T1 mengalami dua kesalahan yaitu gambar yang seharusnya balok dimasukkan ke dalam kategori kubus. T1 mengalami proses asimilasi dan equilibrium karena $\mathrm{T} 1$ dapat menyebutkan alasan memilih gambar-gambar tersebut dengan tepat. T1 mengatakan bahwa balok dan kubus merupakan bangun ruang karena seperti memiliki ruang. Artinya bahwa bangun ruang memiliki tiga dimensi yaitu panjang, lebar dan tinggi. Pada saat ini juga, T1 mengalami proses akomodasi. Proses akomodasi yang dialami T1 ditunjukkan dengan dapatnya $\mathrm{T} 1$ menunjukkan unsur-unsur bangun ruang yaitu 8 titik sudut, 12 rusuk, 6 sisi. Namun T1 mengalami disequlibirium karena tidak dapat dengan jelas membedakan bangun ruang balok dan kubus. Penjelasan pun diberikan kepada T1 bahwa kubus memiliki rusuk yang sama panjang sementara balok tidak memiliki rusuk yang sama panjang.

Selain itu, kubus memiliki bentuk sisi persegi, sementara balok memiliki bentuk sisi persegi panjang. Penjelasan ini membawa T1 mengalami proses equilibrium. Disequilibrium juga dialami T1 pada saat melihat jaringjaring kubus ataupun balok karena mereka secara langsung tidak dapat menjawab pertanyaan yang diberikan.
Pembahasan dilanjutkan pada subjek kedua, T2. T2 merupakan tunagrahita ringan yang kurang jelas dalam berbicara. Sehingga butuh kesabaran dalam mendengarkan penjelasan atau jawaban dari T2. Respon pertama kali ketika diberikan soal adalah bingung sehingga T2 diberi penjelasan mengenai langkah-langkah mengerjakan soal latihan.

T2 mengalami asimilasi ketika T2 dapat menentukan gambar mana yang termasuk bangun datar. T2 menunjukan gambar persegi, lingkaran merupakan bangun datar. Selain itu, proses asimilasi terjadi ketika T2 dapat menyebutkan contoh dari lingkaran yaitu uang logam. Namun T2 mengalami proses disequilibrium ketika tidak dapat menyebutkan contoh dari persegi.

Selanjutnya untuk bangun ruang (balok dan kubus). Terlihat pada gambar 2, T2 mengalami disequilibrium, karena tidak dapat menentukan gambar mana yang merupakan kubus. Ketika ditanya mengapa segitiga merupakan kubus, T2 sama sekali tidak menjawab pertanyaan.

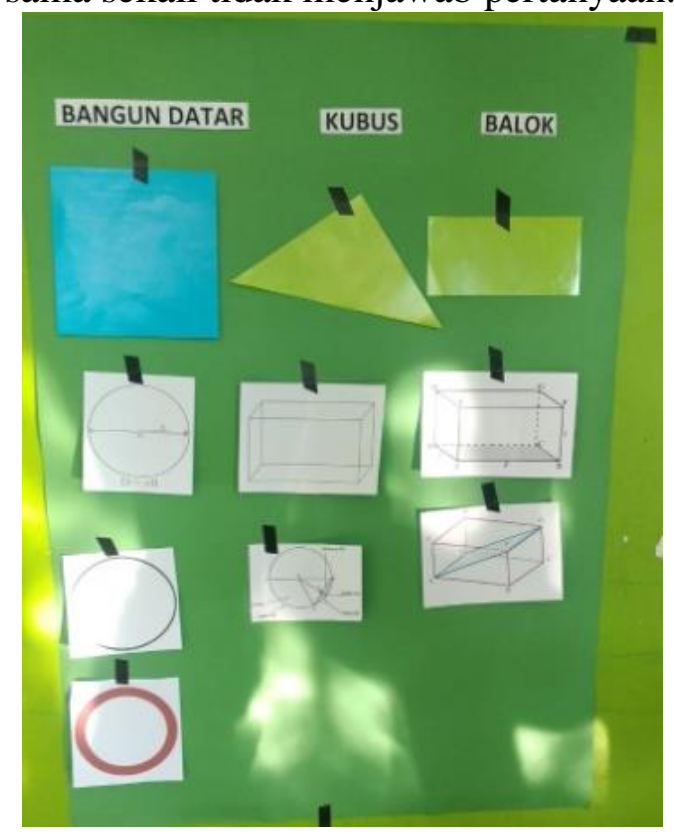

Gambar 2. Hasil Pekerjaan T2 
DOI: https://doi.org/10.24127/ajpm.v10i4.4180

Oleh karena T2 banyak mengalami disequilibrium, maka $\mathrm{T} 2$ diberi penjelasan mengenai bangun datar dan bangun ruang seperti penjelasan kepada T1. Selanjutnya, T2 diminta untuk menunjukkan gambar mana yang merupakan balok. T2 kembali mengalami disequilibrium karena salah menunjukkan bahwa persegi panjang merupakan balok. Namun, hasil yang menarik dari T2 adalah T2 telah mengalami proses equilibrium dan disequilibrium karena ia dapat menghubungkan antara bangun datar persegi panjang dan bangun ruang balok. Ia mengatakan bahwa di dalam balok terdapat persegi panjang, sehingga ia menunjukkan gambar persegi panjang termasuk dalam bangun ruang balok. T2 pun mengalami akomodasi ketika ia dapat menunjukkan titik sudut pada masing-masing gambar, sekaligus disequilibrium ketika ia tidak dapat menunjukkan unsure-unsur bangun datar bangun ruang lainnya. Selanjutnya, T2 diberi pemahaman tambahan mengenai bangun datar dan bangun ruang menggunakan media alat peraga yang telah disiapkan.

Berdasarkan uraian proses berpikir siswa T1 dan T2 menunjukkan bahwa siswa tunagrahita ringan pun mengalami proses berpikir layaknya anak normal. Hal ini sejalan dengan beberapa penelitian yang dilakukan oleh (Agustina, 2021; Usodo et al., 2013). Dalam penelitian ini juga nampak bahwa siswa tunagrahita ringan rupanya dapat mencapai pemahamanpemahaman dasar dalam matematika setelah mereka mengalami beberapa kali disequilibrium. Hal ini bertentangan dengan teori yang diungkapkan oleh Delphie dalam penelitian (Tripuji Lestari, Susanto, \& Fatahillah, 2017) yang mengatakan bahwa siswa yang tergolong anak berkebutuhan khusus dalam hal ini anak tunagrahita (Abdullah, 2013) biasanya gagal dalam mencapai pemahaman dasar-dasar matematika.

Disequilibrium yang dialami kedua siswa tunagrahita ini memang cukup banyak, namun setelah diberi penjelasan berulang-ulang mereka pun paham dan mengalami proses asimilasi. Hal ini menunjukkan bahwa belajar berulang-ulang dapat meningkatkan pemahaman seseorang termasuk anak tunagrahita. Penjelasan berulang-ulang ini perlu dilakukan mengingat kecerdasan intelektual siswa tunagrahita terbatas (Utami et al., 2014).

Satu hal lain yang menarik dari penelitian ini adalah $\mathrm{T} 2$ ternyata mampu mencapai proses equilibrium dimana ia ternyata dapat menunjukkan hubungan antara bangun datar persegi panjang dan bangun ruang balok. Hal ini menunjukkan bahwa beberapa siswa tunagrahita ringan memiliki pemahaman yang cukup bagus untuk beberapa indikator tertentu. Sehingga dalam pembelajarannya, mereka juga perlu diberi kegiatan eksplorasi agar pemahaman mereka dapat terus meningkat melalui media apapun. Hal ini sejalan dengan pendapat yang dikemukakan oleh (Agustina, 2021; Mellawaty \& Lusi Siti Aisah, 2019; Nurfaidah, 2020; Dewi,Y.A.P \& Fami. S, 2018) bahwa pola pendidikan khusus bagi siswa SLB adalah memberikan mata pelajaran umum menggunakan bahasa verbal dan non verbal serta demonstrasi atau eksplorasi dalam pemberian contoh dan media pembelajaran.

\section{KESIMPULAN DAN SARAN}

Berdasarkan hasil dan
pembahasan dapat diberikan
kesimpulan bahwa siswa tunagrahita
ringan lebih banyak mengalami


disquilibrium ketika mereka sama sekali tidak dapat menjawab pertanyaan. Siswa tunagrahita cenderung lebih banyak mengalami disequilibrium karena pada dasarnya mereka mengalami proses berpikir yang lemah sehingga butuh pengulangan untuk membelajarkan matematika. Siswa tunagrahita ringan mengalami proses asimilasi ketika mereka langsung menjawab pertanyaan secara langsung walaupun jawaban yang diberikan tidak diyakini kebenarannya. Sementara proses akomodasi ketika siswa tunagrahita dapat menjawab pertanyaan dengan yakin dan benar. Siswa tunagrahita ringan mengalami equilibrium ketika telah mengalami proses asimilasi dan akomodasi. Dan hanya satu siswa saja yang mengalami equilibrium yang dapat menghubungkan bangun datar dan bangun ruang berdasarkan hasil kegiatan pengamatannya

Kepada para peneliti lain agar dapat melakukan penelitian yang dapat memberikan kontribusi positif kepada para siswa-siswa tunagrahita dalam pembelajaran matematika sehingga dapat memudahkan siswa dalam mengabstrasikan konsep matematika.

\section{DAFTAR PUSTAKA}

Abdullah, N. (2013). Mengenal Anak Berkubutuhan Khusus. Magistra, 25(86), 1-10.

Agustina, Lady. (2021). Proses Berpikir Siswa Tuna Grahita Ringan Dalam Menyelesaikan Masalah Bilangan Bulat Positif Berdasarkan Teori Asimilasi Akomodasi. Sigma, 6(2), 98.

https://doi.org/10.36513/sigma.v6i 2.1004

Aini, N., Susanto, \& Trapsilasiwi, D. (2018). Proses Berpikir Visual Siswa Tunagrahita Ringan Dalam
Memahami Segiempat Berbantuan Media Origami. Kadikma, 3, 1-3. https://doi.org/10.19016/jcshokurik u.3.0_1

Alifah, N., \& Aripin, U. (2018). Proses Berpikir Siswa Smp Dalam Memecahkan Masalah Matematik Ditinjau Dari Gaya Kognitif Field Dependent Dan Field Independent. JPMI (Jurnal Pembelajaran Matematika Inovatif), 1(4), 505. https://doi.org/10.22460/jpmi.v1i4. p505-512

Basori, E. R., \& Gunawan. (2018). Pengaruh Pembelajaran Matematika Realistik terhadap Kemampuan Berhitung Anak Tunagrahita Ringan Kelas 1 di SD Inklusi Glagahwero 01. In Journal of Special Education (Vol. I, pp. $1-5)$.

Fadillatul, H., \& Sopandi, A. A. (2020). Pelaksanaan Pembelajaran Matematika Bagi Anak Tunagrahita Ringan Kelas IX di Slb Negeri 1 Lima Kaum , Kabupaten Tanah Datar. Journal of Multidicsiplinary Research and Development, 2(2), 93-103.

Maulani, F. I., \& Zanthy, L. S. (2020). Analisis Kesulitan Siswa dalam Menyelesaikan Soal Materi Transformasi Geometri. Jurnal Gammath, 5(1), 16-25.

Mellawaty, \& Lusi Siti Aisah. (2019). Integrasi Model Montessori Pada Siswa Tunagrahita Ringan: Eksplorasi, Desain Dan Implementasi Dalam Materi Perkalian. $M A T H L I N E$ : Jurnal Matematika Dan Pendidikan Matematika, 4(2), 139-147.

https://doi.org/10.31943/mathline.v $4 \mathrm{i} 2.114$

Nurfaidah, S. dan M. (2020). Bagaimanakah cara siswa 
DOI: https://doi.org/10.24127/ajpm.v10i4.4180

tunagrahita ringan menyelesaikan soal operasi hitung pembagian?: exploratory case study dalam menggunakan media kotak puzzle geometri. Jurnal Matematika Kreatif Inovatif, 11(2), 143-152.

Piaget, J. (1969). The Psychology Of The Child by Jean Piaget. Retrieved from https://bok.africa/book/2468550/ca8fcd

Pratama, N., Irdamurni, \& Zulmiyetri. (2013). Efektifitas Pembelajaran Matematika Realistik Untuk Meningkatkan Kemampuan Mengenal Bangun Ruang Pada Anak Tunagrahita Ringan. EJUPEKhu, 2(1), 334-342.

Rahman, R. E. A. (2010). Proses Berpikir Siswa tunagrahita Ringan dalam Memahamai Konsep Segitiga Berdasarkan Teori Van Hiele. Jember.

Subanji, R., \& Supratman, A. M. (2015). The Pseudo-Covariational Reasoning Thought Processes in Constructing Graph Function of Reversible Event Dynamics Based on Assimilation and Accommodation Frameworks. Research in Mathematical Education, 19(1), 61-79. https://doi.org/10.7468/jksmed.201 5.19.1.61

Suryadinata, N., \& Farida, N. (2016). Analisis Proses Berpikir Anak Berkebutuhan Khusus (ABK) Dalam Menyelesaikan Masalah Matematika di SMP Inklusi Kota Metro. AKSIOMA:Jurnal Program Studi Pendidikan Matematika, 5(4), 94-104.
Tripuji Lestari, H., Susanto, \& Fatahillah, A. (2017). Proses Berpikir Siswa Tuna Grahita Sedang dalam Menyelesaikan Soal Cerita Matematika Berdasarkan Tahapan Piaget di SMPLB-C TPA Balung. Kadikma, 8(3), 154-161.

Usodo, B., Sandie, \& Riyadi. (2013). Proses Berpikir Siswa Tunagrahita Ditinjau Dari Perbedaan Gender. Pendidikan Informatika Dan Sains, 2(2), 157-166.

Utami, A. D., Sujadi, I., \& Riyadi. (2014). Strategi Guru dalam Membelajarkan Matematika pada Materi Lingkaran Kepada Anak Tunagrahita. Jurnal Elektronik Pembelejaran Matematika, 2(8), 853-864.

Widyastuti, R. (2015). Proses Berpikir Siswa Dalam Menyelesaikan Masalah Matematika Berdasarkan Teori Polya Ditinjau Dari Adversity Quotient Tipe Climber. Al-Jabar: Jurnal Pendidikan Matematika, 6(2), 183-194. https://doi.org/10.24042/ajpm.v6i2. 48 